\title{
Language Errors in Campus Journalists' News Articles: Its Implication to Writers' Interlanguage
}

\author{
Lyoid C. Hunahunan \\ Surigao Del Sur State University-Tagbina Campus, Tagbina, Philippines
}

\begin{abstract}
This study aimed to reveal the linguistic errors student-writers committed in their news articles. It specifically endeavored to identify and classify the common graphological, lexico-semantic, and grammatical errors in the news articles. The frequency of these errors and the news writers' errordensity index were also determined. In this study, one hundred eighteen news articles of high school journalists were evaluated using the descriptive method via corpus analysis. Errors were categorized using Corder's linguistic levels and were further analyzed using Ferris' model of common writing errors. The study revealed that the most prevalent error among news writers is on the grammatical level with the improper use of verb tenses as the most recurrent error followed by capitalization and word choice. Furthermore, the overall error-density index of all news articles computed at $74 \%$ is deemed 'very problematic' which led to the conclusion that the campus journalists are struggling in the correct application of linguistic rules which affect the content of their news and which may threaten the effective delivery of campus journalism.
\end{abstract}

KEY WORDS: campus journalists, interlanguage, language errors, news articles

\section{INTRODUCTION}

Filipino writers whose first language (L1) is not English are confronted with a greater challenge than those who are native speakers of the said language since aside from learning the mechanics and techniques in writing, the former must also consider the conventions of language including grammar and syntax (Fulwiler \& Hayakawa, 2001). In the context of journalism, the use of English in writing news articles poses difficulties for some Filipino studentjournalists for not only does it demand cognitive analysis of the relevant events but also, it entails linguistic synthesis requiring the strict observance of correct grammar and syntax. With this, writing has become even more difficult for news writers that committing errors in their articles becomes almost inevitable. Hence, to address these linguistic difficulties of the school paper-writers, this study identified, categorized and evaluated the errors committed by the campus journalists in their news articles in order to provide an appropriate remedy to their difficulties.

The present study is anchored on Corder's (1974) theoretical and applied objects of error analysis. The theoretical object functions to know what and how a learner learns when he studies a second language while the applied object functions to enable the learner to learn more efficiently by exploiting the knowledge of his dialect for pedagogical purposes.

This error investigation is both diagnostic and prognostic. It is diagnostic as it tells us the learner's state of language competence and prognostic because it tells curriculum planners to revisit language learning materials on the basis of the learners' current problems.

Corder (1982) pointed out that studying the errors committed by second language learners needs no justification as this is something that teachers have always done purely for practical reasons. Corder further explained that understanding the nature of students' errors is indispensable before a systematic way of eradicating them could be found. It is through this analysis that teachers get a deeper understanding of the errors and in effect, design the appropriate teaching strategy, procedures, and materials to eradicate the recurring errors of the students. 
Robinson (2008) asserted that error-making is a natural phenomenon in learning of all kinds. This claim is supported by various studies like that of Alawi (2014), Ullah (2014), Murad (2015), and Tizon (2009) and others which all disclosed the prevalence of errors in students' written compositions. According to Tizon (2009), such errors should be treated by teachers through appropriate strategies for it not to recur over and over again in students' written outputs. This could be addressed through applied error analysis where remedial courses could be organized and appropriate learning materials and teaching strategies could be devised based on the findings of theoretical analysis.

Studies of different researchers, however, like that of the above-mentioned authors, are focused on essays, compositions and other written works that are not specific to journalism. Specifically, studies analyzing errors in news articles of campus journalists are rare. Error-analysis studies in the field of campus journalism should also be considered and given heed since the purpose of news writing is of vital importance not only to the writer himself but to the readers of this news in school who desire to get accurate facts and information about relevant issues in the school community, and also local and national issues relevant to students. To analyze the errors in this journalistic written article means ensuring the quality of journalism in school. Moreover, assessing its quality involves the effective application of grammar and syntax as well as its adherence to the rules and conventions of news writing. This study primarily explored this intent.

The present study could be very beneficial in moving the frontiers in the field of linguistics and campus journalism as its results would provide new evidence as to the nature of second language learning among students and the writers' application of the arts of campus journalism. In other words, by way of investigating the learners' errors in their written articles, teacher-researchers could deduce evidences as to the learners' interlanguage specifically in English. This would also serve as baseline data in providing appropriate intervention to the studentwriters. With this, school paper writers could even more develop their writing competence for them to be apt in their functions as purveyors of information and as vanguards of students' rights. All these will boil down to the ultimate goal of providing and promoting quality campus press in the Philippines as mandated by R.A. 7079 otherwise known as Campus Journalism Act of 1991.

\section{Research Methodology}

This study made use of a descriptive type of research. Moreover, it used the content analysis technique requiring a thorough, careful and exhaustive analysis in identifying and categorizing the errors in the news articles of the campus journalists of Barobo I and II Districts secondary schools in the municipality of Barobo, Surigao del Sur, Philippines. This is a corpusbased study adopting the EA procedures of Corder (1982) in choosing the corpus, identifying, classifying, and evaluating of errors of the studentjournalists' news articles.

For categorization of errors, the study adopted the three linguistic levels of Corder namely: Graphological/Phonological, Lexico-Sematic, and Grammatical levels. The errors were analyzed further using the description of major error categories designed by Ferris (2005). This included the following: a.) verb errors covering errors in verb tense or form, including relevant subject verb-agreement errors; b.) noun-ending errors which cover incorrect plural or possessive ending; c.) article errors including incorrect, omitted, or unnecessary article or other determiner; d.) word wrong which includes all specific lexical errors in word choice or word form, including preposition and pronoun errors; and e.) sentence structure which refers to the errors in sentence/clause boundaries (run-ons, fragments, comma splices), word order, omitted words or phrases, unnecessary words or phrases, or other unidiomatic sentence construction.

In selecting the participants, the researcher employed the universal method of sampling where all the English writers of the school publication were included as respondents in the study. It also utilized the voluntary sampling technique which only included those who are willing to participate as subject of the study.

As a corpus-based study, the primary source of data in this research was the 118 news articles of the secondary school paper writers. Each of the writers was asked to write two news articles based on the news writing prompt which the researcher himself has crafted. This prompt was validated by experts in campus journalism in the Division of Surigao del Sur using a set of criteria reflected on the validation tool. 
The prompt made use of local events in the municipality which was reported in nationally circulating newspapers as bases of the students' news articles for the school paper writers to better understand the context of the news. The two news were reported in the year 2016.

The researcher tabulated, analyzed, and interpreted the data using frequency and percentage distribution to categorize the errors of the respondents' written composition. The error-density index (EDI) was also computed to determine the gravity of errors and decide as to the level of tolerability of campus journalists' writing errors. EDI was computed by getting the quotient of the erroneous independent clauses over the total number of independent clauses (Malicsi, 1995). According to Malicsi, the researcher or teacher has the discretion to determine whether or not the computed EDI of the students passed or failed his/her standard depending upon the objectives of his/her writing exam. In the case of this study, the researcher chose not to use the 'passed' or 'failed' standard as the objective of the study is not on judging the students' writing skills but on evaluating the gravity and level of tolerability of the writers' errors. Hence, in evaluating the magnitude or the level of tolerability of errors, the researcher used his own designed scale as in the following:

\section{EDI}

$0 \%-20 \%$

$21 \%-40 \%$

$41 \%-60 \%$

$61 \%-80 \%$

$81 \%-100 \%$

\section{Verbal Description}

not at all problematic

slightly problematic

moderately problematic

very problematic

completely problematic

As seen in the above scale, a sort of a 5-point scale was adopted where each scale is bracketed in 20 s. As the EDI increases, the level of tolerability also decreases which means that the magnitude of error becomes more problematic.

\section{Results and Discussion}

Table 1 shows the summary of error classification based on the news articles of the campus journalists.

As gleaned from the table, grammatical errors recorded the highest number of errors with a frequency count of 558 or $43 \%$ of the 1,299 total number of errors. This result is a confirmation of Abi Samra (2006) and studies which all disclosed that grammatical errors are the most rampant linguistic problems among students. The graphological error is also considerably high which came in second with 414 or $32 \%$ of the total number of errors. Recording the least number of errors is in the Lexico-Semantic level with 327 or $25 \%$.

Table1. Classification of Errors

\begin{tabular}{|c|c|c|c|}
\hline Type of Error & Total & $\%$ & $\begin{array}{l}\text { Ra } \\
\text { nk }\end{array}$ \\
\hline A. Graphological & 414 & 32 & \\
\hline 1. Punctuation & 111 & 8.5 & 4 \\
\hline 2. Spelling & 57 & 4.4 & 8 \\
\hline 3. Capitalization & 246 & 18.9 & 2 \\
\hline B. Lexico-Semantic & 327 & 25 & \\
\hline 1. Word Choice & 125 & 9.6 & 3 \\
\hline 2. Word Form & 30 & 2.3 & 11 \\
\hline 3. Informal Usage & 9 & 0.7 & 16 \\
\hline 4. Idiom Error & 0 & 0 & 18 \\
\hline 5. Conjunction Error & 15 & 1.2 & 15 \\
\hline 6. Pronoun Error & 50 & 3.8 & 9 \\
\hline 7. Preposition Error & 98 & 7.5 & 5.5 \\
\hline C. Grammatical & 558 & 43 & \\
\hline 1. Verb Tense & 267 & 20.6 & 1 \\
\hline 2. Verb Form & 97 & 7.5 & 5.5 \\
\hline 3. S-V Agreement & 26 & 2.0 & 13 \\
\hline 4. Article/Determiner & 34 & 2.6 & 10 \\
\hline $\begin{array}{l}\text { 5. Noun Endings } \\
\text { (plural/possessive) }\end{array}$ & 20 & 1.5 & 14 \\
\hline 6. Fragment & 28 & 2.2 & 12 \\
\hline 7. Run-on & 7 & 0.5 & 17 \\
\hline 8. Sentence Structure & 79 & 6.1 & 7 \\
\hline Total & 1299 & $100 \%$ & \\
\hline
\end{tabular}

Considering Ferris' (2005) classification of errors, those that could be classified under Corder's grammatical linguistic level like the verb tense, verb form, and sentence structure are considered serious errors as they hinder communication and they affect the structure of the entire sentence. This goes to show that most of the errors committed by the news writers could possibly prevent the message of the news from being comprehended by the readers which is very essential in news writing. This level, therefore, needs looking into so as not to defeat the ultimate purpose of news writing.

In a closer look, verb tense tops the list of the most recurrent error. This vouches for the findings of Alawi (2014) and Bustomi (2009) who both named verb tense as a common error among learners. In the articles of the school paper writers, it could be 
observed that many writers failed to use the past tense in narrating the events which happened in the past. This goes to prove that most of the writers are not aware of the journalistic rule that news are generally presented using the past form of the verb especially in print media; thus the necessity to revisit this basic rule of news writing.

Capitalization under the graphological level is next in rank as the most problematic category. This result implies that there is a need to review the news writers in the basic mechanics of writing considering that capitalization should have been mastered already in their elementary level of basic education. Furthermore, it was observed that most errors in capitalization are committed in the proper capitalization of titles placed before and after names of persons. This is a manifestation that student-writers are not well-oriented of the Associated Press rule on capitalization of titles, thus the need to orient them on this matter.

Following verb tense and capitalization is word choice under the lexico-semantic level. This signifies that campus journalists are still in the process of exploring the use of words especially those unfamiliar to them and still have to enrich their vocabulary for them to be more competent in the proper use of words. In a casual talk with them, a certain journalist who committed an error on word choice said that she thought it was okay to replace a word with any item synonymous with it. There is, therefore, a need for the students to be explained on the appropriateness of a word in the context as an important element to convey the correct and exact message of the sentence. As Ellis (2005) put it: 'superficial well-formedness only does not make a sentence error-free; it also needs to be appropriate in the communication context.'

In the computed error density index, the result shows that the overall error density index of the 59 campus journalists is $74 \%$. Using the scale on the level of tolerability designed by the researcher, $74 \%$ falls under 'very problematic.' This implies that the density of errors committed by the writers is very alarming. This proves further that the campus journalists, being second language learners of English are quite struggling in expressing their news using the second language.

Looking closely, twenty-six of the 59 writers have an EDI classified as 'completely problematic.' In fact, six of them have even incurred a $100 \%$ error-density index which means that all their clauses are erroneous. Worth mentioning also is that none of the writers got an error-free news article. This signifies that error-making is indeed a natural phenomenon in learning of all kinds (Robinson, 2008). This also supports Edge's (2009) contention that learning a second language is always attended by errors. Furthermore, Olasehinde's (2006) argument on the inevitability of error-making among learners is also fortified by these results. This shows that errors are unavoidable and a necessary part of learning. This magnitude of error as gleaned in the overall density index needs due consideration otherwise, the delivery of high-quality news will be affected.

\section{Conclusion}

Drawn from the findings of this study, the researcher has established that errors are really inevitable among campus journalists being second language learners of English as posited by a number of authors. Specifically, campus journalists need to be reviewed in the proper use of the verb tense, capitalization, and word choice in order for them to master their competency in these aspects. In addition to this, from among Corder's three levels, the grammatical level needs due consideration and utmost concentration being the most problematic level among the news writers. Moreover, the overall density of errors committed by the news writers is very alarming which means that they are struggling in the correct application of the rules of mechanics, semantics, grammar, and syntax in English. This implies that there is a necessity to improve strategies used and approaches in teaching the linguistic rules in order to effect a more effective way of learning the linguistic rules which the students have not yet mastered. With this considerable density of errors, the researcher further concludes that there is really a dire need to conduct intervention activities and programs to address the linguistic difficulties of the campus journalists.

\section{References}

1. Abisamra, A. (2006). An analysis of errors in Arabic speakers' English writings. Retrieved September 21, 2016 from http://abisamra03.tripod.com/ /languageacqerroranalysis.html

2. Alawi, T. (2014). An error analysis on academic writing: a look into the interlanguage of university 
students. SDSSU Multidisciplinary Research Journal. Vol. 2 No. 2.

3. Bustomi, A. (2009). An error-analysis on students' descriptive writing. Master's Thesis. State Islamic University. Retrieved September 11, 2016 from http://www.readingmatrix.com/conference/pp/pro ceedings0 05/bustomi.pdf

4. Corder, S.P. (1982). Error Analysis and Interlanguage. Retrieved from http://www. [S._P._Corder]_Error_Analysis_and_Interlanguag e(BookFi.org).pdf

5. Edge, J. (2009). Mistakes and Corrections. London: Longman.

6. Ellis, R. (2005). Two approaches for investigating second language acquisition in context. In $\mathrm{R}$. Ellis (Ed.), Second Language Acquisition in Context. London: Prentice-Hall.

7. Erdogan, V. (2005). Contribution of error analysis to foreign language teaching. Retrieved September 18, 2016 from http://efd.mersin.edu.tr/dergi/meuefd_2005_001_0 02/pdf/meuefd_2005_001_002_02610270_erdoga n.pdf

8. Ferris, D.R. (2005).Treatment of error in second language writing. Ann Arbor: The University of Michigan Press.
9. Fulwiler, T., and Hayakawa, A. R. (2001). The Blair handbook. New Jersey: Prentice Hall, Inc.

10. Malicsi, J. (1995). Error Analysis for College English Teaching. Journal of Asian English Studies, Vol. 1 Nos. $1 \& 2$.

11. Murad, T. (2015). Analysis of errors in English writings committed by Arab first-year college students of the EFL in Israel. Retrieved September 18, 2016 from http://dx.doi.org/10.17507//jltr.0603.02

12. Olasehinde, M. O. (2006). Error analysis and remedial pedagogy. In Babatunde $\mathrm{S}$. T. and D. S. Adeyanju (eds.). Language, meaning and society. Ilorin: Itaytee Press and Publishing Co., Nigeria.

13. Robinson, P.J. (2008). A Hallidayan framework for vocabulary teaching: an approach to organizing the lexical content of an efl syllabus. Retrieved August 19, 2016 from http://www.vocabularyteaching.com/hallidayanefl

14. Tizon, M. (2009). Error-analysis of LSU students' written composition. Master's Thesis. La Salle University. Retrieved August 16, 2016 from http://www.academia.edu/ language studies/htms.

15. Ullah, M. (2014). Analysis of the language errors in writing among BSEE and $A B$ English students. Retrieved August 19, 2016 from http://www.euroessays.org 